\title{
CARACTERIZAÇÃO FÍSICO-MECÂNICA DE BIOFILMES COMESTÍVEIS À BASE DE GELATINA E DE AMIDOS DE MILHO E MANDIOCA
}

\author{
R. C. ALVES ${ }^{1}$, P. B. RIBEIRO ${ }^{1}$, L. P. RICARDO ${ }^{1}$, M. M. MORAIS $^{1}$ e G. S. ROSA ${ }^{1}$ \\ ${ }^{1}$ Universidade Federal do Pampa, Curso de Engenharia Química \\ E-mail para contato: rafaelalvessete3@gmail.com
}

\begin{abstract}
RESUMO - As embalagens de alimentos são de extrema importância na preservação das características físicas, químicas e organolépticas e no aumento do tempo de prateleira dos mesmos. Filmes e recobrimentos comestíveis, à base de biopolímeros como o amido e a gelatina são alternativas na preservação dos alimentos e no combate à poluição gerada pelas embalagens convencionais. Neste trabalho avaliaram-se propriedades físicas e mecânicas de biofilmes produzidos a partir de três diferentes matrizes biopoliméricas - gelatina e amidos de milho e mandioca, com glicerol como plastificante. Os resultados para espessura média dos biofilmes produzidos mostraram que não houve diferença estatística significativa entre os diferentes tipos de biofilmes. Os resultados para tensão de ruptura e alongamento, bem como o aspecto visual dos materiais obtidos, indicaram que os biofilmes produzidos à base de gelatina foram os mais indicados para a proteção e valorização visual de alimentos.
\end{abstract}

\section{INTRODUÇÃO}

Nos dias atuais, a preocupação com o desenvolvimento tecnológico sustentável, do ponto de vista ambiental, tem sido o norte seguido por aqueles que se comprometem a desenvolver novos materiais.

Plásticos sintéticos são extensivamente usados em embalagens de produtos como alimentos, fármacos, cosméticos, detergentes e químicos (Shah et al., 2008). Até agora plásticos à base de petroquímicos como o polietileno tereftalato (PET), policloreto de vinila (PVC), polietileno (PE), polipropileno (PP), poliestireno (PS) e poliamida (PA) têm sido cada vez mais utilizados como material de embalagem, devido à sua grande disponibilidade a custo relativamente baixo e por causa de sua boa performance mecânica, como resistência à tração, boa barreira ao oxigênio, dióxido de carbono, anidridos e componentes aromáticos, capacidade de selagem de calor, e assim por diante (Siracusa et al., 2008). Contudo, de acordo com Schllemer (2011), devido à sua estabilidade estrutural, resistência química, física e à deterioração biológica, seu descarte pode acarretar sérios problemas ambientais, impulsionando a necessidade de desenvolvimento e implementação de materiais alternativos.

Embalagens alimentares têm como objetivo a preservação e proteção de todos os tipos de alimentos, particularmente da deterioração oxidativa e microbiológica, e também de 
estender seu prazo de validade (Tharanathan, 2003). Devem também prover proteção contra o desgaste mecânico durante o transporte e a estocagem.

Recentemente, surgiu um grande interesse no desenvolvimento de biofilmes (filmes biodegradáveis), principalmente devido à demanda por alimentos de alta qualidade, preocupações ambientais sobre o descarte de materiais não renováveis de embalagem para alimentos e oportunidades para criar novos mercados para matérias-primas formadoras de filme, provenientes de produtos agrícolas (Palmu, 2003). Os filmes e coberturas possuem a função de inibir ou reduzir a migração de umidade, oxigênio, dióxido de carbono, lipídios, aromas, dentre outros, pois promovem barreiras semipermeáveis (Fakhouri et al., 2007a). Ainda, aliar estas propriedades à qualidade de comestibilidade torna-se interessante, principalmente na preservação de alimentos in natura cujo tempo de prateleira é bastante curto, como frutas e hortaliças.

Uma cobertura comestível é uma fina camada de material comestível que reveste um alimento, enquanto que um filme comestível consiste em um material fino pré-formado, também de material comestível, que pode ser colocado sobre o alimento ou entre componentes dele. A principal diferença entre esses sistemas é que uma cobertura comestível é aplicada na forma líquida, usualmente por imersão do produto em uma solução geradora formada pela matriz estrutural (carboidrato, proteína, lipídio ou mistura multicomponente), e um filme comestível é primeiramente moldado como uma folha sólida, que é então aplicada como um invólucro sobre o produto alimentício (Falguera et al., 2011).

De acordo com Inamura (2008), a gelatina é um polímero natural que consiste de uma mistura de proteínas de origem animal, solúvel em água quente, glicerol e ácido acético, que embora não seja encontrada in natura pode ser obtida a partir de colágeno por denaturação térmica e ação hidrolítica. Sendo amplamente utilizada na indústria a preços relativamente baixos, justificando assim o grande interesse em seu uso devido às suas propriedades multifuncionais: habilidade de formar géis estáveis e reversíveis (Roman e Sgarbieri, 2007). O amido é também um polímero natural, renovável, de baixo custo e biodegradável e apresenta-se como uma boa alternativa na produção de filmes e recobrimentos comestíveis. Entretanto, filmes a partir deste material necessitam a adição de um plastificante que lhe conceda flexibilidade. Os plastificantes devem ser compatíveis com o biopolímero e a melhor combinação com os filmes de amido é o glicerol e o sorbitol, que interagem com as cadeias do amido, aumentando a mobilidade molecular e a flexibilidade dos seus filmes, embora possam aumentar a hidrofilicidade e permeabilidade ao vapor de água dos mesmos (SHIMAZU et al., 2007).

O objetivo deste trabalho foi avaliar propriedades físicas e mecânicas - nomeadamente espessura e resistência à tensão e alongamento - de filmes comestíveis à base de gelatina e amidos de milho e de mandioca, sob efeito plastificante de glicerol e com água como solvente.

\section{MATERIAIS E MÉTODOS}

Os insumos utilizados nas soluções filmogênicas para a formação de filmes comestíveis biodegradáveis foram: gelatina, amidos de milho e de mandioca comerciais, glicerol e água. 
Para a análise dos biofilmes foram utilizados um paquímetro digital para análise de espessura e um texturômetro (TA.XT plus Texture Analyser) para as análises de tensão de ruptura, conforme a Figura 1.

Figura 1- Análise de tensão de ruptura e alongamento em uma amostra de filme biodegradável.

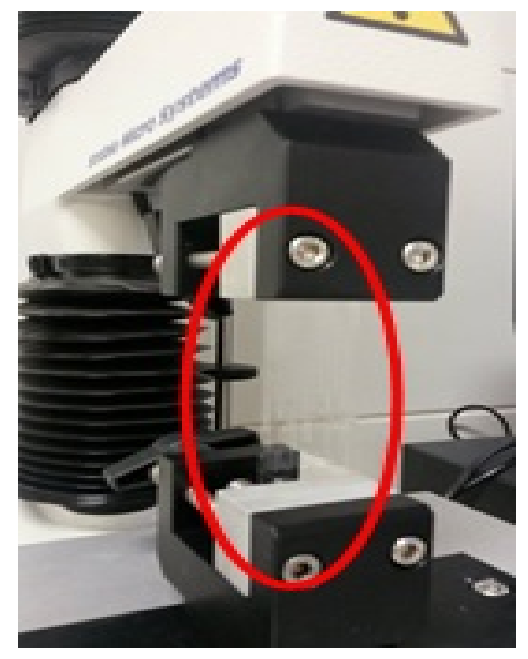

As três soluções filmogênicas estudadas foram preparadas adicionando-se $1 \mathrm{~g}$ de polímero, 0,3 g de plastificante e $100 \mathrm{~mL}$ de água. O fluxograma da Figura 1 apresenta a metodologia empregada na obtenção dos filmes.

Figura 2 - Metodologia de preparo dos biofilmes.

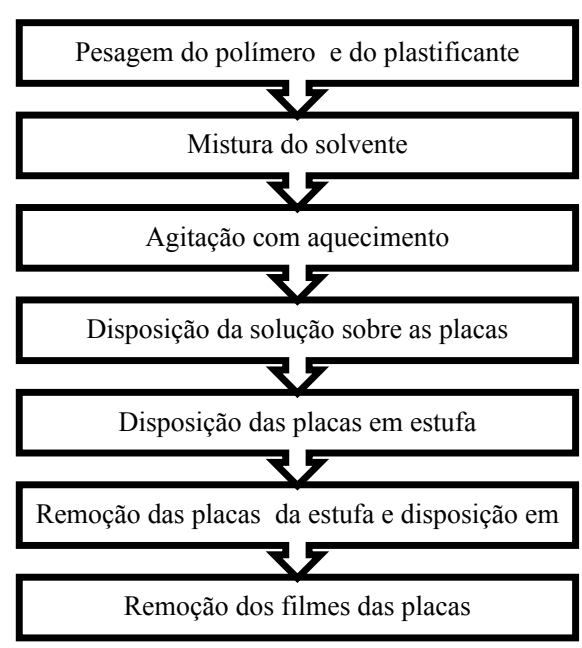

As misturas filmogênicas foram obtidas através da metodologia de casting. Após pesagem dos sólidos e do plastificante em balança analítica digital e adição de água a mistura foi agitada em agitador magnético com aquecimento, com rotação de $1100 \mathrm{rpm}$ e temperatura de $70{ }^{\circ} \mathrm{C}$ por um período de $30 \mathrm{~min}$, para que ocorresse a gelatinização e a formação de gel, a partir dos amidos. 
As soluções foram então despejadas sobre placas de petri de acrílico, de diâmetro 15 $\mathrm{cm}$, e levadas à estufa, devidamente nivelada, a uma temperatura de $40{ }^{\circ} \mathrm{C}$ por um período de $24 \mathrm{~h}$, a fim de evaporar o solvente e obter os biofilmes. Após o período de secagem, as placas foram retiradas da estufa e colocadas em dessecador para retirarem-se os filmes das placas após $24 \mathrm{~h}$.

A espessura média dos biofilmes produzidos foi obtida medindo-se a espessura, com paquímetro digital, de dez pontos distintos e aleatórios. As análises de tensão de ruptura e alongamento foram realizadas utilizando-se um e uma célula de carga de $50 \mathrm{~N}$. As amostras dos biofilmes foram cortadas em formato retangular $(2,5 \times 10 \mathrm{~cm})$ para serem colocadas no texturômetro, fixando uma distância de $50 \mathrm{~mm}$ entre as garras e utilizando velocidade de 50 $\mathrm{mm} / \mathrm{min}$ (ASTM, 2000a). Os parâmetros avaliados foram calculados através das Equações 1 e 2:

$$
\begin{aligned}
& T=\frac{F_{m}}{A} \\
& E \%=\frac{d_{r}-d_{\text {inicial }}}{d_{\text {inicial }}} \times 100
\end{aligned}
$$

em que T é a tensão obtida quando as amostras são expostas à tração (MPa), ${ }^{F}$ é a força máxima de ruptura do filme $(\mathrm{N})$, A é a área da seção transversal do filme $\left(\mathrm{m}^{2}\right), \mathrm{E} \%$ é o alongamento do material, $d_{r}$ é a distância no momento da ruptura $(\mathrm{cm})$, que corresponde à diferença entre a distância de separação no momento da ruptura e a distância incial, e $d_{\text {inicial }}$ é a distância incial (pré estabelecida, em $\mathrm{cm}$ ).

Souza (2011), Vicentino et al. (2011), Moura (2012), entre outros autores que analisaram filmes biodegradáveis realizaram o teste de Tukey para verificar se havia diferenças significativas entre as diferentes formulações elaboradas. Nesse trabalho também foi realizado o teste de Tukey, a partir dos resultados obtidos para espessura, tensão de ruptura e alongamento.

\section{RESULTADOS E DISCUSSÃO}

A Figura 3 apresenta os filmes obtidos após remoção das placas de petri.

Figura 3 - Biofilmes após secagem do solvente.

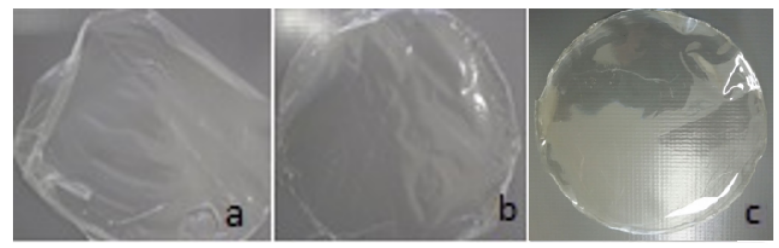

*a) amido de milho; b) amido de mandioca; c) gelatina.

A partir da Figura 3 pode-se observar que os filmes à base de amido de milho apresentaram aspecto mais esbranquiçado e opaco, enquanto que os filmes à base de gelatina 
apresentaram melhor aspecto visual, transparente e brilhante, por ser um hidrocolóide com capacidade de formar filmes flexíveis e géis termorreversíveis.

A Tabela 1 apresenta os resultados para as espessuras médias e para as tensões de ruptura e alongamentos dos filmes estudados.

Tabela 1 - Resultados para espessura média, tensão de ruputura e alongamento.

\begin{tabular}{cccc}
\hline Filme & Espessura $(\mathrm{mm})$ & Tensão $(\mathrm{MPa})$ & Alongamento (\%) \\
\hline $\mathrm{a}$ & $0,05 \pm 0,01^{\mathrm{a}}$ & $1,32 \pm 0,55^{\mathrm{a}}$ & $0,76 \pm 0,11^{\mathrm{a}}$ \\
$\mathrm{b}$ & $0,06 \pm 0,02^{\mathrm{a}}$ & $0,68 \pm 0,52^{\mathrm{a}}$ & $0,71 \pm 0,21^{\mathrm{a}}$ \\
$\mathrm{c}$ & $0,04 \pm 0,01^{\mathrm{a}}$ & $9,11 \pm 1,23^{\mathrm{b}}$ & $0,19 \pm 0,10^{\mathrm{b}}$ \\
\hline
\end{tabular}

De acordo com a Tabela 1, para a análise estatística do teste de tukey, a espessura não diferiu significativamente dentre os diferentes filmes. Assim, os valores para espessura média podem indicar que a dependência desta é basicamente, da quantidade de sólidos secos utilizada na formação dos filmes, não havendo, portanto, expansão ou contração da matériaprima, mas uma mudança na rigidez da mesma, provocada pela ação do plastificante.

Também, segundo a Tabela 1, o maior resultado de tensão obtido foi de 9,11 $\pm 1,23$ $\mathrm{MPa}$, para o filme biodegradável de gelatina, enquanto que a menor foi para o filme composto por amido de mandioca, 0,68 $\pm 0,52 \mathrm{MPa}$. Quanto ao alongamento, o maior resultado deu-se para o filme 1, à base de amido de milho, sendo $0,76 \pm 0,11 \%$, e o menor para o filme de gelatina $0,19 \pm 0,10 \%$. Geralmente, os revestimentos devem ser resistentes à quebra e abrasão, para proteger a estrutura do alimento, e flexíveis, para que possam se adaptar à possível deformação do alimento sem se romperem (Guilbert et al., 1996). Partindo desse conceito, nota-se que o filme à base de gelatina, atende ao primeiro parâmetro citado pelo autor, já que apresentou uma alta tensão de ruptura, porém, baixo alongamento, o que o prejudicaria na boa aderência ao alimento. Já o filme composto em $100 \%$ por amido de milho, teve um maior alongamento em relação aos outros filmes, mostrando boa flexibilidade.

O teste de Tukey foi realizado para uma diferença mínima significativa ao nível de $5 \%$, e mostrou para o teste de tensão e para o alongamento que apenas o filme biodegradável à base de gelatina diferiu significativamente dos biofilmes à base de amido.

\section{CONCLUSÃO}

Dentre as formulações para biofilmes elaboradas aquela à base de gelatina foi a que apresentou maior tensão de ruptura e, portanto, é a mais indicada à proteção do alimento, por ser mais resistente. $\mathrm{O}$ filme composto de amido de milho obteve maior alongamento em relação às demais formulações. Logo apresenta-se como o mais flexível e adaptável à superfície do alimento a ser revestido.

Visualmente, o filme biodegradável à base de gelatina foi o mais atrativo, pois teve um aspecto brilhante e transparente, valorizando a aparência da fruta, enquanto os filmes de amidos tiveram sua coloração mais opaca. Dessa maneira, constata-se que o filme biodegradável à base de gelatina é o mais recomendado para os fins de proteção e valorização visual do produto a ser revestido. 


\section{REFERÊNCIAS}

FAKHOURI, F. M.; FONTES, L. C. B., CONÇALVES, P. V. de M. Filmes e coberturas comestíveis à base de amidos nativos e gelatina na conservação e aceitação sensorial de uvas Crimson. Ciênc. Tecnol. Aliment., v. 27, p. 369-375, 2007.

FALGUERA, V.; QUINTERO, J. P.; JIMÉNEZ, A.; MUÑOZ, J. A.; IBARZ, A. Edible films and coatings: Structures, active functions and trends in their use. Trends Food Scien. \& Technol., v. 22, p. 292-303, 2011.

GUILBERT, S.; LEON, N. G.; GORRIS, L. G. M. Prolongation of the shelf-life of perishable food products using biodegradable films and coatings. Lebensm.-Wiss. u.-Technol., v. 29, p. 10-17, 1996.

INAMURA, P. Y. Efeito da radiação gama sobre a viscosidade de soluções de gelatina e pectina utilizadas na indústria de alimentos. Dissertação (Mestrado em Ciências) Instituto de Pesquisas Energéticas e Nucleares, autarquia associada à Universidade de São Paulo, São Paulo - SP, 2008, 78 p.

PALMU, P. S. T. Preparação, propriedades e aplicação de biofilmes comestíveis à base de glúten de trigo. Tese (doutorado) - Faculdade de Engenharia de Alimentos, Universidade Estadual de Campinas, Campinas - SP, 2003. 244 p.

ROMAN, J. A.; SGARBIERI, V. C. Caracterização físico-química do isolado protéico de soro de leite e gelatina de origem bovina. Braz. J. Food Technol., v. 284, p. 137-243, 2007.

SHAH, A. A.; HASAN, F.; HAMEED, A.; AHMED, S. Biological degradation of plastics: A comprehensive review. Biotechnol. Advan., v. 26, p. 246-265, 2008.

SHCLEMMER, D. Estudo das propriedades de nanocompósitos amido/montmorilonita, utilizando óleos vegetais como plastificantes. Dissertação (Programa de pós-graduação em Química) - Laboratório de Pesquisa em Polímeros, Universidade de Brasília, Brasília - DF, 2011. 170 p.

SIRACUSA, V.; ROCCULI, P.; ROMANI, S.; ROSA, M. D. Biodegradable polymers for food packaging: a review. Trends Food Scien. \& Technol., v. 19, p. 634-643, 2008.

THARANATHAN, R. N. Biodegradable films and composite coatings: past, present and future. Trends Food Scien. \& Technol., v. 14, p. 71-78, 2003.

VIEIRA, M. G. A.; SILVA, M. A. da; SANTOS, L. O.; BEPPU, M. M. Natural-based plasticizers and biopolymer films: A review. Eur. Pol. J., v. 47, p. 254-263, 2011. 